\title{
Hérnia Perineal Primária: Relato de Caso
}

\author{
Primary Perineal Hernia: Case Report
}

\section{HERNÁN AUGUSTO CENTURIÓN SOBRAL'; JULIANA SUAREZ WOLF²; RODRIGO BRITTO DE CARVALHO²; JULIANA MAGALHÃES LOPES²; GALDINO JOSÉ SITONIO FORMIGA³}

${ }^{1}$ Médico Preceptor do Serviço de Coloproctologia do Hospital Heliópolis, FSBCP. ${ }^{2}$ Médico Residente do Serviço de Coloproctologia do Hospital Heliópolis. ${ }^{3}$ Chefe do Serviço de Coloproctologia do Hospital Heliópolis, TSBCP.

\begin{abstract}
SOBRAL HAC; WOLF JS; CARVALHO RB; LOPES JM; FORMIGA GJS. Hérnia Perineal Primária: Relato de Caso. Rev bras Coloproct, 2009;29(1): 102-105.

RESUMO: As hérnias perineais primárias resultam de um defeito no assoalho pélvico que permite a passagem de conteúdo abdominal para a região pelve-perineal. É uma enfermidade rara, tendo sido descritos menos de cem casos até hoje. Apresentamos o caso de uma paciente jovem com queixa recente de tumoração glútea dolorosa que, mesmo após o exame físico e tomográfico, não teve sua etiologia esclarecida. Foi então submetida à ressecção cirúrgica da lesão via perineal, quando se confirmou tratarse de saco herniário isquiorretal esquerdo transpondo defeito no músculo elevador do ânus. Evoluiu sem intercorrências no pósoperatório e sem indícios de recidiva.
\end{abstract}

Descritores: Hérnia perineal; hérnia pélvica; hérnia isquiorretal; hérnia congênita; hérnia pudenda.

\section{INTRODUÇÃO}

Hérnia perineal primária, também denominada de hérnia pélvica, isquiorretal, pudenda e do fundo de saco de Douglas, foi descrita inicialmente por Garengeot em 1736 e resulta da formação espontânea de um defeito na musculatura do assoalho pélvico com consequente herniação do conteúdo peritoneal ${ }^{1,2}$.

Devido a sua raridade e às diversas formas de apresentação e tratamento, relatamos um caso desta enfermidade, com uma breve revisão da literatura.

\section{RELATO DO CASO}

Mulher de 32 anos, multípara (três partos normais), há três meses com tumoração dolorosa em nádega esquerda, associada a relato de drenagem de abscesso nesta região há dois anos. O exame proctológico revelou abaulamento em reto e canal anal, extendendo-se ao períneo e nádega esquerdos, de aproximadamente $10 \mathrm{~cm}$ de diâmetro, consistência cística e sem sinais flogísticos. CT pélvica evidenciou cole- ção homogênea, contornos regulares, limites bem definidos, comprimindo a parede póstero-lateral esquerda do reto, deslocando anteriormente bexiga e vagina e estendendo-se para fossa isquiorretal homolateral (Figura 1).

Submetida a tratamento cirúrgico via perineal, através de uma incisão longitudinal na região glútea es-

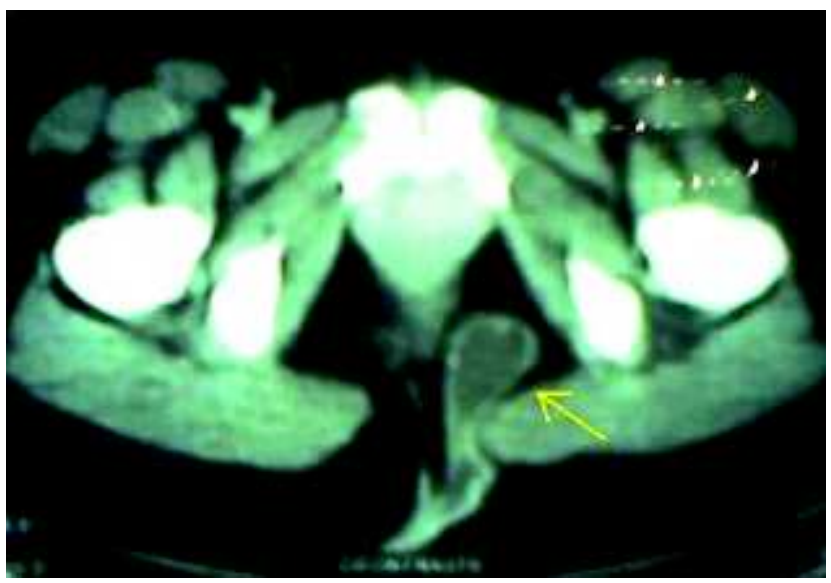

Figura $1-C T$ de pelve demonstrando lesão cística em fossa isquiorretal esquerda.

Trabalho realizado no Serviço de Coloproctologia do Hospital Heliópolis - São Paulo - SP - Brasil.

Recebido em 08/10/2008

Aceito para publicação em 20/11/2008 
querda, abertura da fossa isquiorretal e dissecção da lesão cística com aspecto semelhante a saco herniário cranialmente até o assoalho pélvico, próximo à tuberosidade isquiática (Figura 2). À abertura da peça, observou-se continuidade com a cavidade peritoneal,

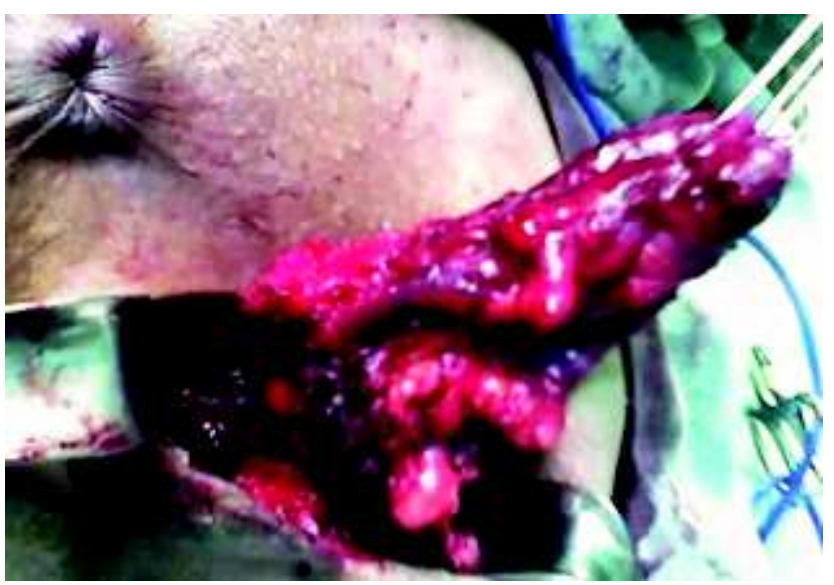

Figura 2 - Dissecção da lesão na fossa isquiorretal esquerda até o músculo elevador do ânus.

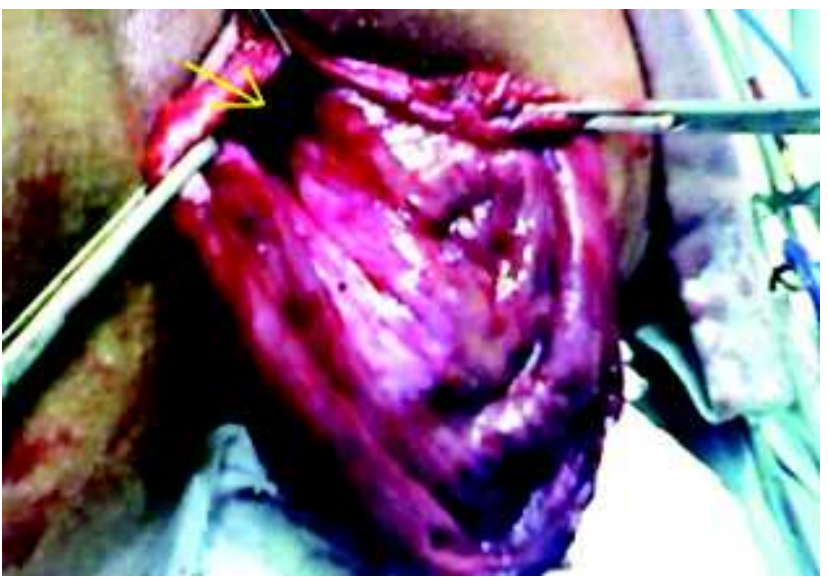

Figura 3-Abertura da peça demonstrando ausência de vísceras e continuidade com a cavidade peritoneal.

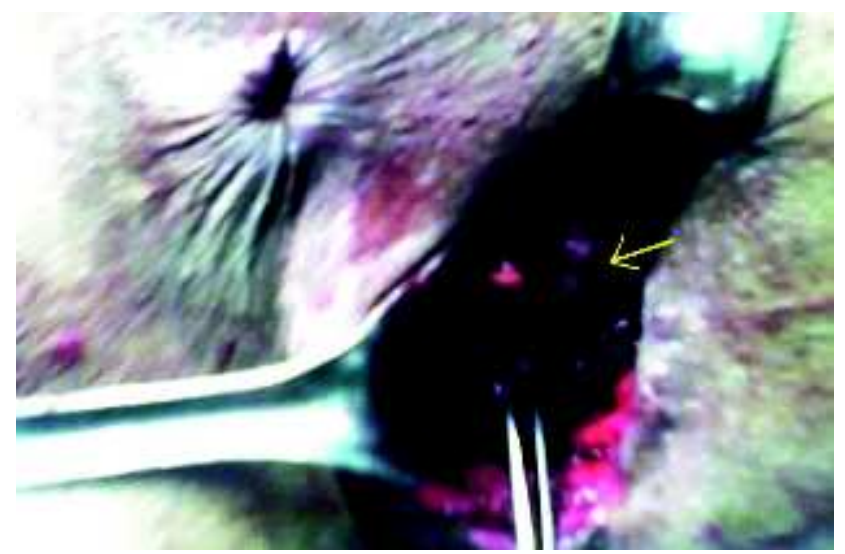

Figura 4 - Colo do saco herniário suturado. presença de conteúdo líquido amarelo citrino e sem alças intestinais (Figura 3). O excesso do saco foi ressecado e sua base suturada, realizada aproximação dos planos anatômicos, além de drenagem com Penrose do espaço remanescente (Figuras 4 e 5).

Estudo anátomo-patológico mostrou tratar-se de tecido fibroadiposo correspondente a parede de saco herniário peritoneal, ratificando o diagnóstico (Figuras 6 e 7).

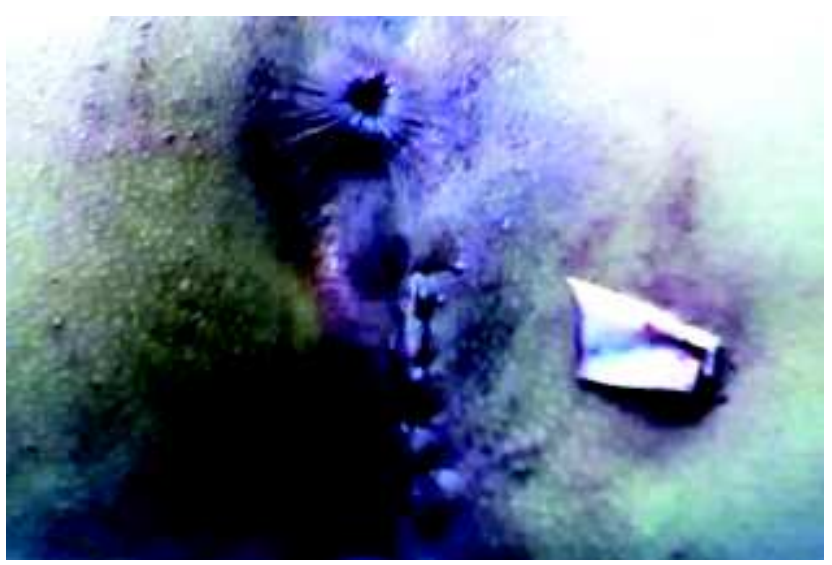

Figura 5 - Aspecto ao final da cirurgia.

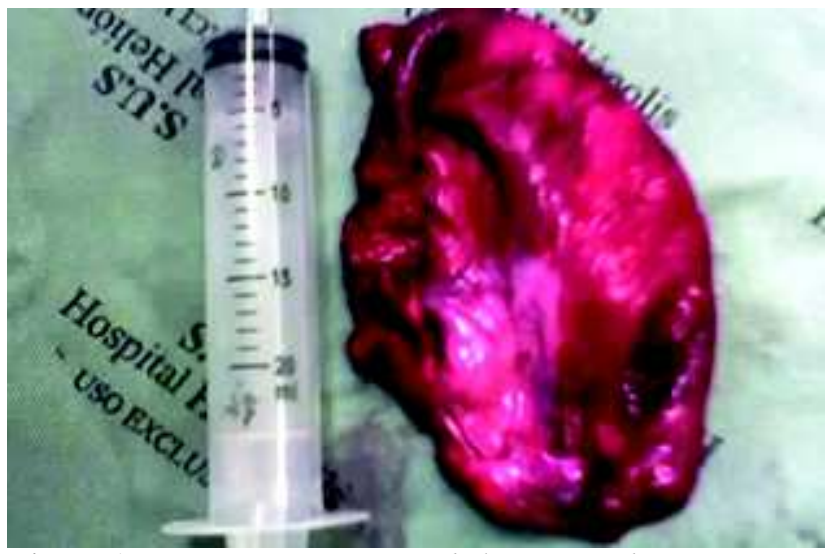

Figura 6 - Aspecto macroscópico da lesão (saco herniário).

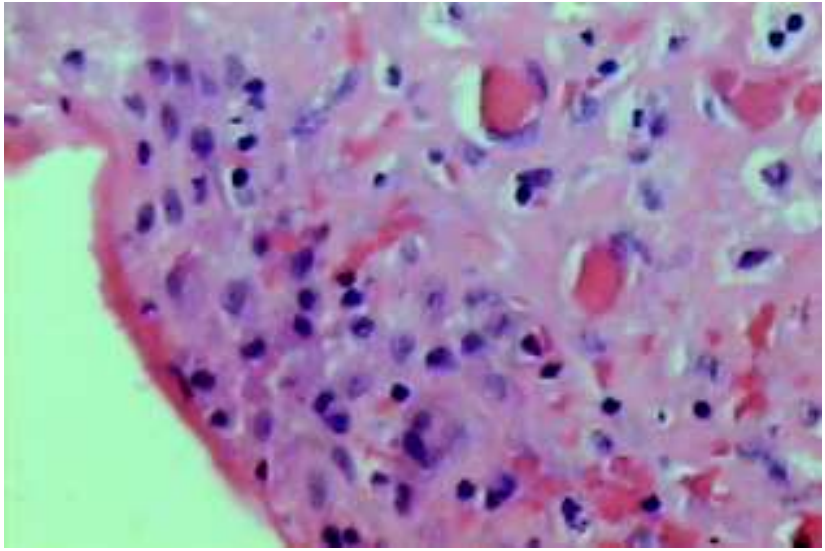

Figura 7-Microscopia óptica com coloração HE compatível com tecido peritoneal. 
Evoluiu sem intercorrências no pós-operatório imediato, estando em acompanhamento ambulatorial há onze meses sem sinais de recidiva.

\section{DISCUSSÃO}

As hérnias perineais são raras, sendo relatados menos de cem casos na literatura mundial consultada ${ }^{1-3}$. Acometem pacientes entre a quinta e sétima décadas de vida, sobretudo mulheres numa proporção de $5: 1^{1-4,6}$.

Os distúrbios associados são, principalmente, fraqueza do assoalho pélvico relacionada a trauma obstétrico (provavelmente o que acontecera com nossa paciente), tosse crônica, obesidade, ascite ou outras formas de aumento da pressão intra-abdominal, como também pelve larga tipo ginecóide, fundo de saco de Douglas profundo e defeitos congênitos da musculatura pélvica ${ }^{1-7}$.

Podem ser classificadas em primárias ou secundárias, estando estas últimas relacionadas a ressecções cirúrgicas pelve-perineais prévias como amputação abdomino-perineal do reto e exenterações pélvicas. Já as formas primárias podem ser subdivididas em medianas, quando relacionadas à profundidade anormal do fundo de saco, provocando abaulamento na parede posterior da vagina ou anterior do reto (enteroceles); e laterais, tanto anteriores, devido a defeito no diafragma urogenital, como posteriores, em virtude de falha nos músculos elevadores do ânus, a depender da relação topográfica do saco herniário com o músculo transverso profundo do períneo ${ }^{1-5,7}$. Em se tratando do caso em questão, foi classificado como hérnia primária lateral e posterior, por ser espontânea e encontrar-se posteriormente ao músculo transverso profundo do períneo.
O quadro clínico caracteriza-se por tumoração amolecida, dolorosa e eventualmente redutível em grandes lábios, períneo ou glúteos, podendo associar-se a distúrbios miccionais e evacuatórios, sendo pouco freqüentes os quadros obstrutivos agudos por estrangulamento do conteúdo herniário ${ }^{1-6}$. Entretanto, muitas outras condições mais comuns mimetizam massas perineais e glúteas, como hamartomas, lipomas, cistos, sobretudo os de Bartholin, retoceles e cistoceles, prolapso retal e, principalmente, abscessos anorretais $^{1,2,6}$.

Em virtude do exame físico geralmente não acrescentar dados significantes ao diagnóstico clínico, deve-se lançar mão de exames de imagem, inicialmente através de radiografias simples ou contrastadas (enema opaco) da pelve e períneo, com intuito de identificar presença de alças intestinais nestas regiões ${ }^{1-6}$. A confirmação é feita pela ecografia, tomografia computadorizada ${ }^{1-6}$ ou ressonância nuclear magnética ${ }^{5}$, as quais evidenciarão parede e conteúdo do saco herniário, como alças, bexiga, omento ou ascite.

Como qualquer outra forma de hérnia, o tratamento é cirúrgico ${ }^{1-7}$. Nas hérnias perineais podem-se efetuar tanto abordagens perineais, na presença de hérnias laterais pequenas, como abdominais, na suspeita de encarceramento, ou procedimentos mistos, indicados nas hérnias mediais e laterais volumosas, sendo estes últimos os mais realizados, associados ou não à interposição de telas ou fáscias ao defeito anatômico ${ }^{1-}$ ${ }^{6}$. Optamos por abordagem perineal exclusiva devido à dúvida diagnóstica e por tratar-se de saco herniário lateral de tamanho médio e sem conteúdo visceral, efetuando a correção do defeito sem necessidade do uso de próteses.

ABSTRACT: Primary perineal hernias result from a defect in the pelvic floor. It is a rare disease, having been described less than one hundred cases until today. We present a case of a young patient with recent complaint of painful gluteal tumor that even after the physical examination and CT did not clarified its etiology. She was submitted to a perineal resection of the lesion that confirmed being a hernia. She is going well without recurrence.

Key words: Perineal hernia; pelvic hernia; ischiorectal hernia; congenital hernia; pudendal hernia.

\section{REFERÊNCIAS}

1. Thomford NR, Sherman NJ. Primary perineal hernia. Dis Colon Rectum 1969; 12(6): p 441-443.

2. Mandarano R, Giorgi G, Venturini N, Mancini E, Natale A, Tiburzi C. Ernia perineale. Minerva Chir 1999; 54: p 523529.
3. Cali RL, Pitsch RM, Blatchford GJ, Thorson A, Christensen MA. Rare pelvic floor hernias. Dis Colon Rectum 1992; 35(6): p 604-612.

4. Mohta A, Bhargava SK. Congenital perineal hernia: report of a case. Surg Today 2004; 34: p 630-631.

5. Singh K, Reid WMN, Berger LA. Translevator gluteal hernia. Int Urogynecol J 2001; 12: p 407-409. 
6. Salum MR, Prado-Kobata MH, Saad SS, Matos D. Primary perineal posterior hernia. An abdominoperineal approach for mesh repair of the pelvic floor. Clinics 2005; 60(1): p 71-74.

7. Sarr MG, Stewart JR, Cameron JC. Combined abdominoperineal approach to repair of postoperative perineal hernia. Dis Colon Rectum 1982; 25(6): p 597-599.

\section{Endereço para correspondência:} HERNÁN AUGUSTO CENTURIÓN SOBRAL

Serviço de Coloproctologia do Hospital Heliópolis Rua Cônego Xavier, 276. Vila Heliópolis

04231-030 - São Paulo - SP - Brasil

Fone: (11) 2274-7600 (ramal 244)

E-mail: hacsobral@uol.com.br 